\title{
Risk factors and correlation of colorectal polyps with type 2 diabetes mellitus
}

\author{
Jin $\mathrm{Xu}^{\#}$, Wei He", Nannan Zhang, Nan Sang, Junning Zhao \\ Department of Gastroenterology, Geriatric hospital of Nanjing Medical University, Jiangsu Province Geriatric Hospital, Nanjing, China \\ Contributions: (I) Conception and design: J Xu, J Zhao; (II) Administrative support: J Zhao; (III) Provision of study materials or patients: J Xu, W He, \\ N Zhang; (IV) Collection and assembly of data: J Xu, W He, N Sang; (V) Data analysis and interpretation: J Xu, W He, N Sang; (VI) Manuscript \\ writing: All authors; (VII) Final approval of manuscript: All authors. \\ \#These authors contributed equally to this work. \\ Correspondence to: Junning Zhao. Department of Gastroenterology, Geriatric hospital of Nanjing Medical University, Jiangsu Province Geriatric \\ Hospital, Nanjing 210029, China. Email: zj11102@163.com.
}

Backgrounda Colorectal polyp is a common disease of the gastrointestinal tract, which is closely related to colorectal cancer. Diabetes mellitus (DM) is a major public health disease that seriously threatens human health. This study aimed to investigate the risk factors of colorectal polyps and its relationship with type 2 DM (T2DM).

Methods: A total of 352 patients with colorectal polyps (diagnosed by colonoscopy) in our hospital from June 2018 to June 2020 were enrolled as the observation group, and 201 healthy people with normal colonoscopy results were selected as the control group. The levels of blood lipids, blood glucose, liver function, serum uric acid (UA), and glycosylated hemoglobin (HbA1c) were compared between the two groups. Univariate and multiple logistic regression analyses were performed to analyze the risk factors related to colorectal polyps.

Results: Compared to the control group, the levels of HbAlc, fasting plasma glucose (FPG), 2-hour post-meal blood glucose (2hPG), total cholesterol (TC), and serum UA in the observation group were significantly higher $(\mathrm{P}<0.05)$. Univariate analysis showed that the incidence of colorectal polyps was significantly correlated with gender, smoking, age, non-alcoholic fatty liver disease (NAFLD), and type 2 diabetes mellitus $(\mathrm{T} 2 \mathrm{DM})(\mathrm{P}<0.05)$. Multiple Logistic regression analysis showed that gender (male), age ( $\geq 60$ years), and T2DM were independent risk factors for colorectal polyps $(\mathrm{P}<0.05)$.

Conclusions: Abnormal metabolic indices may be closely related to the development of colorectal polyps. Gender (male), age ( $\geq 60$ years), smoking, NAFLD, T2DM, as well as increased blood glucose, UA, and TC were identified as the risk factors for colorectal polyps.

Keywords: Colorectal polyps; risk factor; type 2 diabetes mellitus (T2DM); non-alcoholic fatty liver disease (NAFLD); blood glucose

Submitted Dec 07, 2021. Accepted for publication Jan 30, 2022.

doi: 10.21037/apm-21-3943

View this article at: https://dx.doi.org/10.21037/apm-21-3943

\section{Introduction}

Colorectal polyp is a common disease of digestive tract, which is closely related to colorectal cancer (1-3). Some subsets of adenomatous polyps and hyperplastic polyps are considered to be precursors of hereditary and sporadic colorectal cancer, and approximately $50-70 \%$ of colorectal cancer originates from adenomatous polyps $(4,5)$. Colorectal cancer develops mainly via the colorectal adenoma (CRA)carcinoma sequence, and hyperplastic polyps can also progress to colorectal cancer through microsatellite instability (6-8). In recent decades, the incidence rates 
of both colorectal polyps and colorectal cancer have been increasing. In 2018, there were approximately 1.4 million new colorectal cancer cases and 700,000 deaths worldwide (7). Therefore, understanding the related risk factors of colorectal polyps will be helpful to effectively avoid risk factors, which is of crucial for the prevention of colorectal cancer (9).

It has been shown that the risk factors of colorectal cancer include age, dietary habit, obesity, alcohol abuse, smoking, as well as personal or family history of colon cancer or adenomatous polyps $(9,10)$. Among these, familial multiple adenomatous disease and hereditary nonpolyposis colorectal cancer have the greatest impact on the incidence of colorectal cancer $(11,12)$. It is known that the precancerous lesions of colorectal cancer mainly include CRA, ulcerative colitis and familial genetic diseases, etc. (13). Among these, CRA belongs to the most common category, accounting for $85-90 \%$ or even higher of the precancerous lesions of colorectal cancer (14). At present, the "CRAcarcinoma sequence" is considered one of the internationally recognized tumorigenesis patterns of colorectal cancer (6). It can be inferred that if the pathogenesis and risk factors of CRA can be clarified, and CRA can be treated more quickly and effectively (such as by colonoscopic resection), the incidence and mortality rates of colorectal cancer can be significantly reduced $(15,16)$.

Diabetes mellitus (DM) is a major public health disease that seriously threatens human health. Diabetes can be mainly divided into two types: type 1 diabetes mellitus (T1DM) and type 2 diabetes mellitus (T2DM), with T2DM being a more common type $(17,18)$. T2DM is a type of noninsulin-dependent DM which is mainly insulin resistance and insufficient insulin secretion (19). Diabetes is not only known to cause various blood vessels and neuropathy, but also closely related to the occurrence and development of many malignant tumors, especially digestive tract tumors (20). At present, studies have shown that T2DM is a risk factor for malignant tumors, and patients with $\mathrm{T} 2 \mathrm{DM}$ are at a higher risk of developing malignancies than those without T2DM $(21,22)$. T2DM is an independent risk factor for colorectal cancer (21). In terms of the pathogenesis of the disease, the precipitating factor of CRA is an inducement factor of T2DM, and it can be assumed that T2DM is also the precipitating factor of CRA.

In recent years, the relationship between T2DM and CRA has attracted increasing attention, and has become the focus of research in the field of cancer prevention and treatment (23). Although T2DM is an independent risk factor for colorectal cancer, research on the relationship between T2DM and colorectal adenomatous polyps has made some achievements. However, the relationship between T2DM and colorectal polyps remains controversial. In this study, we collected the data of patients who underwent colonoscopy in our hospital in the past 2 years, and the related risk factors of colorectal polyps and their relationship with T2DM were further investigated, to provide evidence for the association between T2DM and colorectal polyps. We present the following article in accordance with the STROBE reporting checklist (available at https://apm.amegroups.com/article/view/10.21037/apm$21-3943 / \mathrm{rc})$.

\section{Methods}

\section{Patients}

A total of 352 patients (aged $45-72$ years, with an average age of $57.23 \pm 6.85$ years) with colorectal polyps diagnosed by colonoscopy in our hospital from June 2018 to June 2020 were enrolled into the observation group. Also, 125 patients in this group had $\leq 2$ polyps, and 227 patients had $>2$ polyps. Moreover, there were 256 cases of polyp size $\leq 10 \mathrm{~mm}$, and 96 cases $>10 \mathrm{~mm}$. There were 183 cases of adenomatous polyps and 169 cases of non-adenomatous polyps.

Furthermore, a total of 201 healthy people (aged $44-73$ years, with an average of $56.85 \pm 5.46$ years) who showed normal colonoscopy results were selected as the control group. There was no significant difference in basic data between the two groups $(\mathrm{P}>0.05)$.

As per instructions of the Ethics Committee of the Geriatric Hospital of Nanjing Medical University (Jiangsu Province Geriatric Hospital), informed consent was provided by the patients before commencement of the study. The study was approved by the Ethics Committee of the Geriatric hospital of Nanjing Medical University (Jiangsu Province Geriatric Hospital) (No. 2020-014), and was conducted in accordance with the Declaration of Helsinki (as revised in 2013).

\section{Inclusion criteria and exclusion criteria}

Inclusion criteria: (I) colorectal polyps were diagnosed by colonoscopy in our hospital, including hyperplastic polyps and colorectal adenomatous polyps, etc.; (II) the pathological results were benign; and (III) patients with complete medical records. 
Table 1 Comparisons of HBA1c, FPG, 2hPG, FCP, and FINS between the two groups

\begin{tabular}{lccccc}
\hline Groups & HBA1c $(\%)$ & FPG $(\mathrm{mmol} / \mathrm{L})$ & FCP $(\mathrm{ng} / \mathrm{mL})$ & FINS $(\mathrm{mU} / \mathrm{L})$ & $2 \mathrm{hPG}(\mathrm{mmol} / \mathrm{L})$ \\
\hline Observation & $5.86 \pm 0.78^{\star \star}$ & $5.82 \pm 0.82^{*}$ & $2.88 \pm 0.23$ & $16.45 \pm 0.49$ & $6.92 \pm 0.30^{\star}$ \\
Control & $5.72 \pm 0.69$ & $5.48 \pm 0.76$ & $2.73 \pm 0.48$ & $15.37 \pm 0.14$ & $6.78 \pm 0.59$ \\
\hline
\end{tabular}

The data were presented as mean \pm standard deviation (SD). * $\mathrm{P}<0.05 ;{ }^{* *}, \mathrm{P}<0.01$. HbA1c, glycosylated hemoglobin; FPG, fasting plasma glucose; FCP, fasting C-peptide; FINS, fasting insulin; 2hPG, 2-hour post-meal blood glucose.

Table 2 Comparisons of blood lipids, liver function, and uric acid between the two groups

\begin{tabular}{lccccccc}
\hline Groups & TC $(\mathrm{mmol} / \mathrm{L})$ & $\mathrm{TG}(\mathrm{mmol} / \mathrm{L})$ & $\mathrm{HDL}-\mathrm{C}(\mathrm{mmol} / \mathrm{L})$ & $\mathrm{LDL}-\mathrm{C}(\mathrm{mmol} / \mathrm{L})$ & $\mathrm{UA}(\mu \mathrm{mol} / \mathrm{L})$ & AST $(\mathrm{mmol} / \mathrm{L})$ & $\mathrm{ALT}(\mathrm{mmol} / \mathrm{L})$ \\
\hline Observation & $4.98 \pm 1.20^{*}$ & $1.67 \pm 1.13$ & $1.27 \pm 0.55$ & $5.60 \pm 35.39$ & $342.66 \pm 89.17^{* *}$ & $21.70 \pm 12.80$ & $24.13 \pm 24.45$ \\
Control & $4.77 \pm 0.98$ & $1.64 \pm 1.59$ & $1.27 \pm 0.31$ & $4.95 \pm 26.84$ & $326.766 \pm 82.26$ & $22.07 \pm 15.71$ & $23.58 \pm 29.88$ \\
\hline
\end{tabular}

The data were presented with mean \pm standard deviation (SD). * $\mathrm{P}<0.05$; ${ }^{* *}, \mathrm{P}<0.01$. TC, total cholesterol; TG, triglyceride fatty acid; HDL-C, high-density lipoprotein cholesterol; LDL-C, low-density lipoprotein cholesterol; UA, serum uric acid; AST, aspartic transaminase; ALT, alanine aminotransferase.

Exclusion criteria: (I) other intestinal diseases (such as colorectal cancer, intestinal tuberculosis, inflammatory bowel disease, acute and chronic enteritis, familial adenomatous polyposis, etc.); (II) patients with other serious basic diseases (such as viral or drug-induced hepatitis, chronic kidney disease, etc.); (III) patients who underwent colorectal surgery; and (IV) pregnant and lactating patients.

\section{General data}

The general data of the enrolled patients were analyzed retrospectively, including gender, age, smoking, alcohol intake, T2DM, non-alcoholic fatty liver disease (NAFLD), hyperlipidemia, coronary heart disease, hypertension, and hyperuricemia, etc. The glycosylated hemoglobin (HbA1c), 2-hour post-meal blood glucose (2hPG), fasting bloodglucose (FPG), fasting C-peptide (FCP), fasting insulin (FINS), serum total cholesterol (TC), triglyceride fatty acid (TG), high-density lipoprotein cholesterol (HDL-C), low-density lipoprotein cholesterol (LDL-C), aspartic transaminase (AST), alanine aminotransferase (ALT), and serum uric acid (UA) of all enrolled patients were recorded.

\section{Statistical analysis}

The data were statistically analyzed by SPSS26.0 (IBM, Chicago, IL, USA). The measurement data were expressed as mean \pm standard deviation (SD), and comparison between the groups was performed by one-way analysis of variance (ANOVA). Counting data were expressed by the rate, and the chi square test was used for comparison between the groups. The risk factors of colorectal polyps were analyzed by multivariate logistic regression. $\mathrm{P}<0.05$ was considered statistically significant.

\section{Results}

\section{Comparisons of HBA1c, FPG, 2hPG, FCP and FINS between the two groups}

The levels of HbA1c, FPG, and 2hPG in the observation group were significantly higher than those in the control group $(\mathrm{P}<0.05)$. There were no significant differences in FCP and FINS between the observation group and the control group $(\mathrm{P}>0.05)$. The details are shown in Table 1 .

\section{Comparisons of blood lipids, liver function, and UA between the two groups}

The levels of TC and UA in the observation group were significantly higher than those in the control group $(\mathrm{P}<0.05)$. The levels of TG, HDL-C, LDL-C, AST, and ALT in the observation group were not significantly different from those in the control group $(\mathrm{P}>0.05)$. The details are displayed in Table 2.

\section{Univariate analysis of risk factors related to colorectal polyps}

The results of univariate analysis showed that there were 
Table 3 Univariate analysis of risk factors related to colorectal polyps

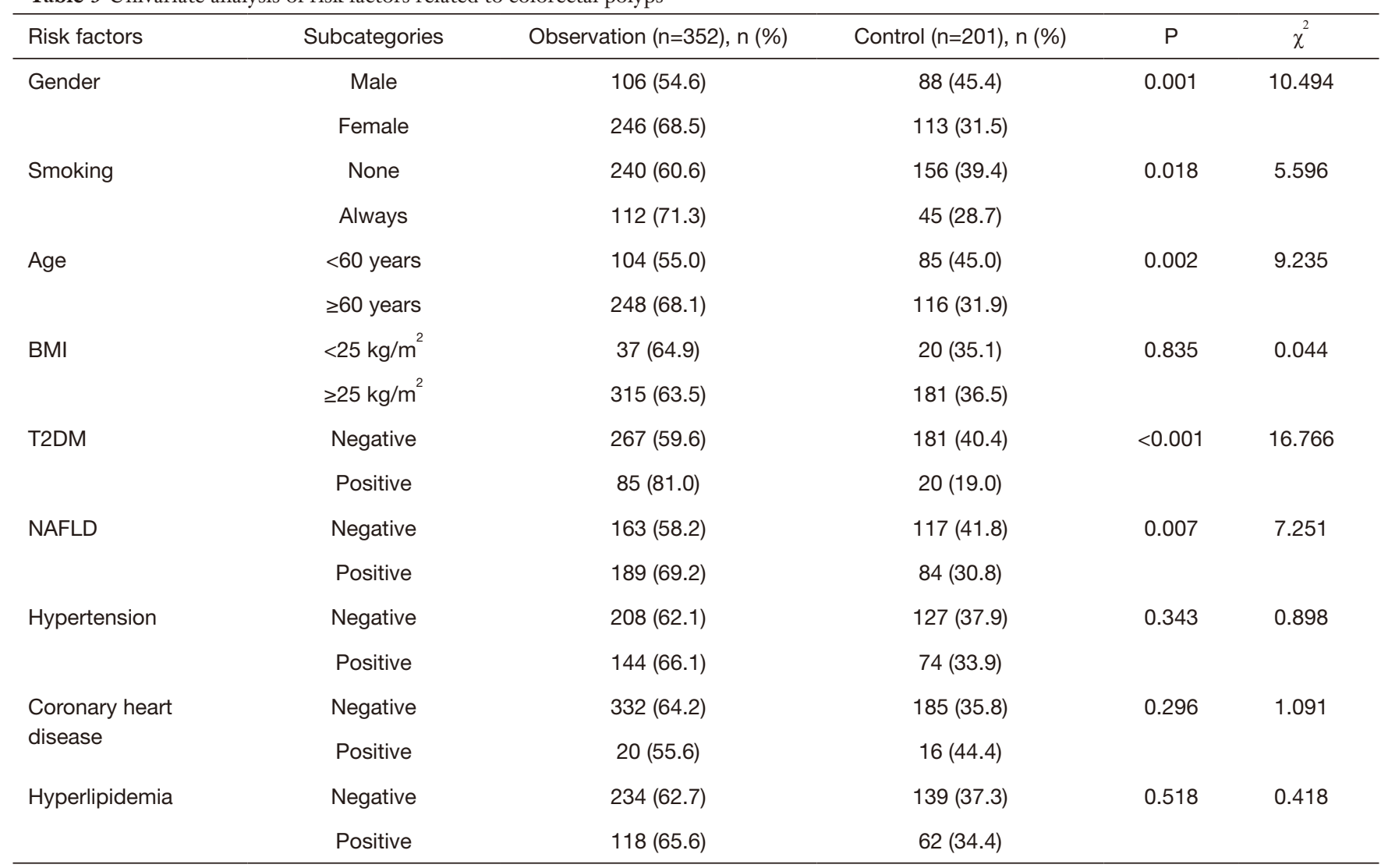

BMI, body mass index; T2DM, type 2 diabetes mellitus; NAFLD, non-alcoholic fatty liver disease.

significant differences in gender, smoking, age, T2DM, and NAFLD between the observation and control groups $(\mathrm{P}<0.05)$; however, no significant differences in body mass index (BMI), hypertension, coronary heart disease, and hyperlipidemia were observed $(\mathrm{P}>0.05)$. The details are shown in Table 3.

\section{Multiple logistic regression analysis of risk factors related to colorectal polyps}

Factors that showed statistical differences in the univariate analysis were included in the binary logistic regression analysis. The results showed that gender (male) [odds ratio $(\mathrm{OR})=1.703,95 \%$ confidence interval $(\mathrm{CI}): 1.129,2.570$, $\mathrm{P}=0.011$, age ( $\geq 60$ years) $(\mathrm{OR}=0.574,95 \%$ CI: $0.386,0.852$, $\mathrm{P}=0.006)$, and T2DM (OR $=0.400,95 \%$ CI: 0.231, 0.693, $\mathrm{P}=0.001)$ were independent risk factor for colorectal polyps. The results are displayed in Table 4.

\section{Discussion}

In recent years, the incidence rate of colorectal cancer in China has been increasing annually. Presently, colorectal cancer has the second highest incidence rate among digestive system diseases, and the highest incidence rate among malignant tumors in China $(24,25)$. Clinical data has demonstrated that colorectal cancer can not only be found early, but can also be prevented by endoscopic resection of colorectal polyps $(3,26)$. Most colorectal cancers develop from colorectal polyps, which are recognized as precursor lesions based on epidemiological, histological, and genetic studies $(7,27)$. Therefore, investigating the relevant risk factors of colorectal polyps is an important strategy to reduce the risk of colorectal cancer, as well as early evaluation of asymptomatic individuals, regular screening of high-risk groups with colonoscopy, and improving the detection rate of precancerous lesions and early colorectal 
Table 4 Multiple logistic regression analysis of risk factors related to colorectal polyps

\begin{tabular}{|c|c|c|c|c|c|}
\hline Risk factors & $\beta$ & Standard error & OR & $95 \% \mathrm{Cl}$ & $\mathrm{P}$ \\
\hline Age ( $\geq 60$ years) & -0.556 & 0.202 & 0.574 & $0.386,0.852$ & 0.006 \\
\hline T2DM & -0.916 & 0.280 & 0.400 & $0.231,0.693$ & 0.001 \\
\hline $\operatorname{BMI}\left(\geq 25 \mathrm{~kg} / \mathrm{m}^{2}\right)$ & 0.264 & 0.313 & 0.768 & $0.416,1.420$ & 0.400 \\
\hline Hyperlipidemia & 0.068 & 0.212 & 1.071 & $0.706,1.624$ & 0.748 \\
\hline Hypertension & 0.044 & 0.205 & 1.045 & $0.699,1.564$ & 0.829 \\
\hline NAFLD & -0.311 & 0.196 & 0.733 & $0.499,1.077$ & 0.113 \\
\hline Coronary disease & 0.564 & 0.370 & 1.757 & $0.850,3.631$ & 0.128 \\
\hline
\end{tabular}

OR, odds ratio; $\mathrm{Cl}$, confidence interval; BMI, body mass index; T2DM, type 2 diabetes mellitus; NAFLD, non-alcoholic fatty liver disease.

cancer.

Numerous studies have confirmed that the incidence of colorectal polyps increases with age (5). The risk of colorectal polyps increases by 1.03 times with a 1 -year increase in age (28). Lieberman et al. reported that the colonoscopy results of 327,785 patients in the United States showed that the incidence rate of colorectal polyps increased with age, and the incidence rate in males was higher than that in females (29). In this study, age was significantly higher, with more male and smokers in the observation group compared to the control group. Univariate and multivariate logistic regression analyses further confirmed that age and gender were independent risk factors for colorectal polyps. Clendenen et al. showed that estrogen can delay the development of colorectal cancer by reducing the level of secondary bile acids and down regulating insulin-like growth factor-1 (IGF-1) (30). Tobacco contains carcinogens and is thought to cause irreversible genetic damage to colonic mucosa, thereby triggering the formation of colorectal polyps (31). Therefore, smokers may have a high incidence rate of colorectal polyps.

At present, multiple studies have found that hyperlipidemia, NAFLD, and metabolic syndrome are high-risk factors for colorectal polyps $(5,10)$. Some studies have found that high levels of TC and TG are closely related to the pathogenesis of colorectal polyps (32). The present study found that the levels of TC and UA in the observation group were significantly higher than those in the control group, suggesting that hypercholesterolemia and hyperuricemia play an important role in the pathogenesis of colorectal polyps. The effect of high cholesterol level on colorectal polyps may be related to the production of bile acids, and primary bile acids may be related to the risk of CRA by stimulating the proliferation of crypt cells (33). Elevated serum UA is a marker of chronic inflammation and has been considered to be associated with an increased cancer risk (34). The possible mechanism is that monosodium urate crystal stimulates the inflammatory response by activating toll-like receptor 4 (TLR4), which strongly promotes the production of pro-inflammatory factors by leukocytes and plays a key role in regulating tumor formation and cancer progression (35). NAFLD is considered to be the manifestation of metabolic syndrome in the liver. Chen et al. revealed that NAFLD was associated with an increased risk of CRA and hyperplastic polyps in men (36), which was consistent with the results of this study. The reason for this may be that insulin resistance leads to NAFLD. During insulin resistance, the body's circulating insulin level increases compensation and activates IGF-1. Both can inhibit cell apoptosis, promote cell proliferation and differentiation, and exert carcinogenic effects.

With the improvement of living conditions, the incidence rate of T2DM and colorectal polyps increased significantly (21). The results of this study suggested that the levels of FPG, 2hPG, and HbA1c in the observation group were significantly higher than those in the control group, and T2DM was an independent risk factor for colorectal polyps. Studies have shown that insulin resistance and hyperinsulinemia in T2DM patients may promote carcinogenesis by directly stimulating the proliferation of colorectal cells. In addition, insulin is considered to bind to and activate the IGF-1 receptor, which is expressed 
in normal colorectal epithelial cells and tumor cells (37). Following activation by IGF-1, the receptor-ligand complex can inhibit apoptosis and allow cell cycle progression. In a retrospective study of 3,505 patients in Korea, it was reported that T2DM patients had a higher proportion of adenomatous polyps (38). Additionally, in a case-control study in the United States (261 versus 522 matched controls), it was found that patients with T2DM had an increased risk of colorectal adenomatous polyps (39). But it was noteworthy that chronic insulin therapy is associated with increased risk of CRAs in patients with T2DM. It was reported that aspirin and metformin combination therapy had the chemopreventive effect on aberrant crypt foci (ACF) in T2DM patients. It was supposed that aspirin and metformin combination therapy may be applied for colorectal polyps in T2DM patients.

There were still some limitations in our research that should be noted. Firstly, due to the retrospective design of this study, it is impossible to confirm the accuracy of the information provided by patients, such as height, weight, smoking, and drinking habits, which may have led to misleading results. Secondly, due to the small number of cases, the study population only included patients who had undergone colonoscopy, which may not represent the general population.

In summary, the results of this study showed that the incidence of colorectal polyps was related to gender (male), age ( $\geq 60$ years), smoking, NAFLD, FPG, 2hPG, TC, HbA1c, and UA levels. T2DM was an independent risk factor for colorectal polyps. T2DM and colorectal polyps may have a common pathogenesis and related highrisk factors. These findings are potentially significant for targeted screening of T2DM patients. Early diagnosis with colonoscopy, regular follow-up, and intervention for patients with colorectal polyps are important factors for reducing the incidence and mortality rates of colorectal cancer.

\section{Acknowledgments}

Funding: This study was supported by the Science and Technology Development Fund of Nanjing Medical University (No. NMUB2020185).

\section{Footnote}

Reporting Checklist: The authors have completed the STROBE reporting checklist. Available at https://apm. amegroups.com/article/view/10.21037/apm-21-3943/rc

Data Sharing Statement: Available at https://apm.amegroups. com/article/view/10.21037/apm-21-3943/dss

Conflicts of Interest: All authors have completed the ICMJE uniform disclosure form (available at https://apm. amegroups.com/article/view/10.21037/apm-21-3943/coif). The authors have no conflicts of interest to declare.

Ethical Statement: The authors are accountable for all aspects of the work in ensuring that questions related to the accuracy or integrity of any part of the work are appropriately investigated and resolved. As per instructions of the Geriatric Hospital of Nanjing Medical University (Jiangsu Province Geriatric Hospital), informed consent was provided by the patients before commencement of the study. The study was approved by the Ethics Committee of the Geriatric Hospital of Nanjing Medical University (Jiangsu Province Geriatric Hospital) (No. 2020-014). The study was conducted in accordance with the Declaration of Helsinki (as revised in 2013).

Open Access Statement: This is an Open Access article distributed in accordance with the Creative Commons Attribution-NonCommercial-NoDerivs 4.0 International License (CC BY-NC-ND 4.0), which permits the noncommercial replication and distribution of the article with the strict proviso that no changes or edits are made and the original work is properly cited (including links to both the formal publication through the relevant DOI and the license). See: https://creativecommons.org/licenses/by-nc-nd/4.0/.

\section{References}

1. Rezasoltani S, Asadzadeh Aghdaei H, Dabiri H, et al. The association between fecal microbiota and different types of colorectal polyp as precursors of colorectal cancer. Microb Pathog 2018;124:244-9.

2. Sastre Lozano VM, Morán Sánchez S, García Solano J, et al. Relationship between the polyp detection rate and the post-colonoscopy colorectal cancer rate. Rev Esp Enferm Dig 2019;111:598-602.

3. Shaukat A, Kaltenbach T, Dominitz JA, et al. Endoscopic Recognition and Management Strategies for Malignant Colorectal Polyps: Recommendations of the US Multi-Society Task Force on Colorectal Cancer. Gastroenterology 2020;159:1916-1934.e2. 
4. Alagaratnam S, Loizidou M, Yang SY, et al. Increased expression of IGF-1Ec with increasing colonic polyp dysplasia and colorectal cancer. J Cancer Res Clin Oncol 2020;146:2861-70.

5. Ochiai Y, Inoshita N, Iizuka T, et al. Clinicopathological features of colorectal polyps and risk of colorectal cancer in acromegaly. Eur J Endocrinol 2020;182:313-8.

6. Feng Q, Liang S, Jia H, et al. Gut microbiome development along the colorectal adenoma-carcinoma sequence. Nat Commun 2015;6:6528.

7. Crockett SD, Nagtegaal ID. Terminology, Molecular Features, Epidemiology, and Management of Serrated Colorectal Neoplasia. Gastroenterology 2019;157:949966.e4.

8. Vacante M, Ciuni R, Basile F, et al. Gut Microbiota and Colorectal Cancer Development: A Closer Look to the Adenoma-Carcinoma Sequence. Biomedicines 2020;8:489.

9. He X, Wu K, Ogino S, et al. Association Between Risk Factors for Colorectal Cancer and Risk of Serrated Polyps and Conventional Adenomas. Gastroenterology 2018;155:355-373.e18.

10. Hao Y, Wang Y, Qi M, et al. Risk Factors for Recurrent Colorectal Polyps. Gut Liver 2020;14:399-411.

11. Dinarvand P, Davaro EP, Doan JV, et al. Familial Adenomatous Polyposis Syndrome: An Update and Review of Extraintestinal Manifestations. Arch Pathol Lab Med 2019;143:1382-98.

12. Boland PM, Yurgelun MB, Boland CR. Recent progress in Lynch syndrome and other familial colorectal cancer syndromes. CA Cancer J Clin 2018;68:217-31.

13. Dekker E, Rex DK. Advances in CRC Prevention: Screening and Surveillance. Gastroenterology 2018;154:1970-84.

14. Murakami T, Sakamoto N, Nagahara A. Endoscopic diagnosis of sessile serrated adenoma/polyp with and without dysplasia/carcinoma. World J Gastroenterol 2018;24:3250-9.

15. Seo JY, Chun J, Lee C, et al. Novel risk stratification for recurrence after endoscopic resection of advanced colorectal adenoma. Gastrointest Endosc 2015;81:655-64.

16. Soltani G, Poursheikhani A, Yassi M, et al. Obesity, diabetes and the risk of colorectal adenoma and cancer. BMC Endocr Disord 2019;19:113.

17. Iminger-Finger I, Kargul J, Laurent GJ. Diabetes: Present and future. Int J Biochem Cell Biol 2017;88:196.

18. Harcourt BE, Penfold SA, Forbes JM. Coming full circle in diabetes mellitus: from complications to initiation. Nat Rev Endocrinol 2013;9:113-23.
19. Gloyn AL, Drucker DJ. Precision medicine in the management of type 2 diabetes. Lancet Diabetes Endocrinol 2018;6:891-900.

20. Shlomai G, Neel B, LeRoith D, et al. Type 2 Diabetes Mellitus and Cancer: The Role of Pharmacotherapy. J Clin Oncol 2016;34:4261-9.

21. Berster JM, Göke B. Type 2 diabetes mellitus as risk factor for colorectal cancer. Arch Physiol Biochem 2008;114:84-98.

22. Tsilidis KK, Kasimis JC, Lopez DS, et al. Type 2 diabetes and cancer: umbrella review of meta-analyses of observational studies. BMJ 2015;350:g7607.

23. Yu F, Guo Y, Wang H, et al. Type 2 diabetes mellitus and risk of colorectal adenoma: a meta-analysis of observational studies. BMC Cancer 2016;16:642.

24. Chen H, Li N, Ren J, et al. Participation and yield of a population-based colorectal cancer screening programme in China. Gut 2019;68:1450-7.

25. Zhu J, Tan Z, Hollis-Hansen K, et al. Epidemiological Trends in Colorectal Cancer in China: An Ecological Study. Dig Dis Sci 2017;62:235-43.

26. Dumoulin FL, Hildenbrand R. Endoscopic resection techniques for colorectal neoplasia: Current developments. World J Gastroenterol 2019;25:300-7.

27. Dattani M, Crane S, Battersby NJ, et al. Variations in the management of significant polyps and early colorectal cancer: results from a multicentre observational study of 383 patients. Colorectal Dis 2018;20:1088-96.

28. Han X, Qian W, Liu Y, et al. Effects of age, sex and pathological type on the risk of multiple polyps: A Chinese teaching hospital study. J Dig Dis 2020;21:505-11.

29. Lieberman DA, Williams JL, Holub JL, et al. Race, ethnicity, and sex affect risk for polyps $>9$ $\mathrm{mm}$ in average-risk individuals. Gastroenterology 2014;147:351-8; quiz e14-5.

30. Clendenen TV, Koenig KL, Shore RE, et al. Postmenopausal levels of endogenous sex hormones and risk of colorectal cancer. Cancer Epidemiol Biomarkers Prev 2009;18:275-81.

31. Ji BT, Weissfeld JL, Chow WH, et al. Tobacco smoking and colorectal hyperplastic and adenomatous polyps. Cancer Epidemiol Biomarkers Prev 2006;15:897-901.

32. Yang W, Chang Y, Huang H, et al. Association between Obesity, Serum Lipids, and Colorectal Polyps in Old Chinese People. Gastroenterol Res Pract 2013;2013:931084.

33. Ocvirk S, O'Keefe SJD. Dietary fat, bile acid metabolism and colorectal cancer. Semin Cancer Biol 2021;73:347-55. 
34. Tomizawa M, Shinozaki F, Hasegawa R, et al. Higher serum uric acid levels and advanced age are associated with an increased prevalence of colorectal polyps. Biomed Rep 2015;3:637-40.

35. Rezasoltani S, Ghanbari R, Looha MA, et al. Expression of Main Toll-Like Receptors in Patients with Different Types of Colorectal Polyps and Their Relationship with Gut Microbiota. Int J Mol Sci 2020;21:8968.

36. Chen QF, Zhou XD, Sun YJ, et al. Sex-influenced association of non-alcoholic fatty liver disease with colorectal adenomatous and hyperplastic polyps. World J Gastroenterol 2017;23:5206-15.

Cite this article as: $\mathrm{Xu} \mathrm{J}$, He W, Zhang N, Sang N, Zhao J. Risk factors and correlation of colorectal polyps with type 2 diabetes mellitus. Ann Palliat Med 2022;11(2):647-654. doi: 10.21037/apm-21-3943
37. Strissel PL, Ellmann S, Loprich E, et al. Early aberrant insulin-like growth factor signaling in the progression to endometrial carcinoma is augmented by tamoxifen. Int J Cancer 2008;123:2871-9.

38. Suh S, Kang M, Kim MY, et al. Korean type 2 diabetes patients have multiple adenomatous polyps compared to non-diabetic controls. J Korean Med Sci 2011;26:1196-200.

39. Eddi R, Karki A, Shah A, et al. Association of type 2 diabetes and colon adenomas. J Gastrointest Cancer 2012;43:87-92.

(English Language Editor: A. Kassem) 